\title{
Mean sea level and surface circulation variability of the Mediterranean Sea from 2 years of TOPEX/POSEIDON altimetry
}

\author{
Gilles Larnicol and Pierre-Yves Le Traon \\ Collecte Localisation Satellites, Space Oceanography Group, Toulouse, France \\ Nadia Ayoub and Pierre De Mey \\ Laboratoire d'Océanographie et de Géophysique, CNRS, Toulouse, France
}

\begin{abstract}
We describe the circulation and mean sea level variations of the Mediterranean Sea from 2 years of TOPEX/POSEIDON altimetric data. It is first shown that the response of the Mediterranean Sea to atmospheric pressure forcing is close to an inverse barometer (except at high frequencies) which means that the adjustment is accompanied by a flow through the Straits of Sicily and Gibraltar. We then use TOPEX/ POSEIDON to study the mean sea level variations, representing steric effects and integrated large-scale changes of the mass of the Mediterranean Sea. We observe an annual cycle with a fast drop during winter. Steric effects account for about half of the observed variations. The remaining signal is believed to be driven by evaporation minus precipitation $(\mathrm{E}-\mathrm{P}$ ) forcing and internal hydraulic control in the Straits of Gibraltar. Using suboptimal space-time objective analysis, the classic components of the Mediterranean surface circulation are recovered, despite low signal-to-noise ratio (the rms of sea level variability is less than $10 \mathrm{~cm}$ ). The variable Mediterranean circulation is seen as a complex combination of mesoscale and large-scale variations. The surface circulation is more complex in the eastern basin than in the western basin. In the east it is composed of subbasin-scale gyres, such as the so-called Mersa-Matruh and Shikmona gyres, which do not have an obvious recurrence period. We also observe an intensification of the largescale cyclonic winter circulation in the western and in the Ionian basins. Several mesoscale structures, such as the Alboran gyres and the lerepetra gyre, show a clear seasonal cycle, with a maximum in summer. The good qualitative and quantitative agreement of the results with previous data from the Mediterranean illustrates the improved accurary of TOPEX/POSEIDON over its predecessors.
\end{abstract}

\section{Introduction}

The Mediterranean basin extends over $3000 \mathrm{~km}$ in longitude and over $1500 \mathrm{~km}$ in latitude. The Straits of Sicily separate the western Mediterranean (WM) and eastern Mediterranean (EM) basins, which are themselves composed of the following subbasins: Adriatic, Ionian, and Levantine in the east and Balearic (Liguro-Provencal and Algerian) and Tyrrhenian in the west. A net Atlantic inflow through the Straits of Gibraltar

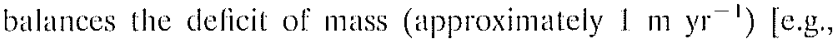
Lacombe and Tchernia, 1972] and the corresponding excess of salt caused by evaporation in excess over precipitation. The fresh Allantic Water (AW) migrates into the WM and $E M$ basins and becomes saltier and denser under the influence of intense air-sea interaction. Levantine Intermediate Water (LIW) is formed during winter convection in the Levantine basin and recirculates at intermediate depth. The LIW eventually exits the Mediterranean via the Straits of Gibraltar. Mediterranean Deep Water (MDW) formation also occurs in the Gulf ol Lions and in the Adriatic Sea, and some MDW may also comprise the Gibraltat outflow [Bryden and Stommel, 1982].

Copyright 1995 by the American Geoplysical Union.

Paper number $955 \mathrm{JC} 01961$.

$0 / 48-0227 / 95 / 95.1 \mathrm{C}-01961 \$ 05.00$
In the last 10 years the understanding of the circulation of the Mediteranean Sea has significantly progressed through programs such as Physical Oceanography of the Eastern Mediterranean (POEM) [Malanotle-Rizzoli and Robinson, 1988] or Western Mediterranean Circulation Experiment (WMCE) [ $\mathrm{La}$ Violette, 1987]. Descriptions of the circulation and its variability are given by Millor [1991] for the western basin and by Robinson et al. [1991] for the POEM Group in the east. These studies reveal that the Meditermean circulation is a combination of mesoscale and seasonal scales. In the west the AW first flows eastward along the Spanish coast, veers south across the Alboran Sea from Alneria to Oran, and forms the unstable Algerian current (Figure 1), whose instabilities generate intense mesoscale activity in the form of anticyclonic eddies and meanders. Other components of the western circulation are the cyclonic gyres in the Tyrrhenian Sea [Krisvoheva and Ovchinikov, 1973], and in the Balearic basin and the LiguroProvençal. The Liguro-Provençal current has a clear seasonal variability [Millot, 1991]. The AW Howing eastward past the Sicily Straits meanders in the Ionian basin and forms the midMediterranean jet. This current is described as being persistent and weak. On both sides of the jet, subbasin gyres can be identified, such as the mather stable cyclonic Rhodes and Ionian gyres to the north and the seemingly transient anticyclonic 


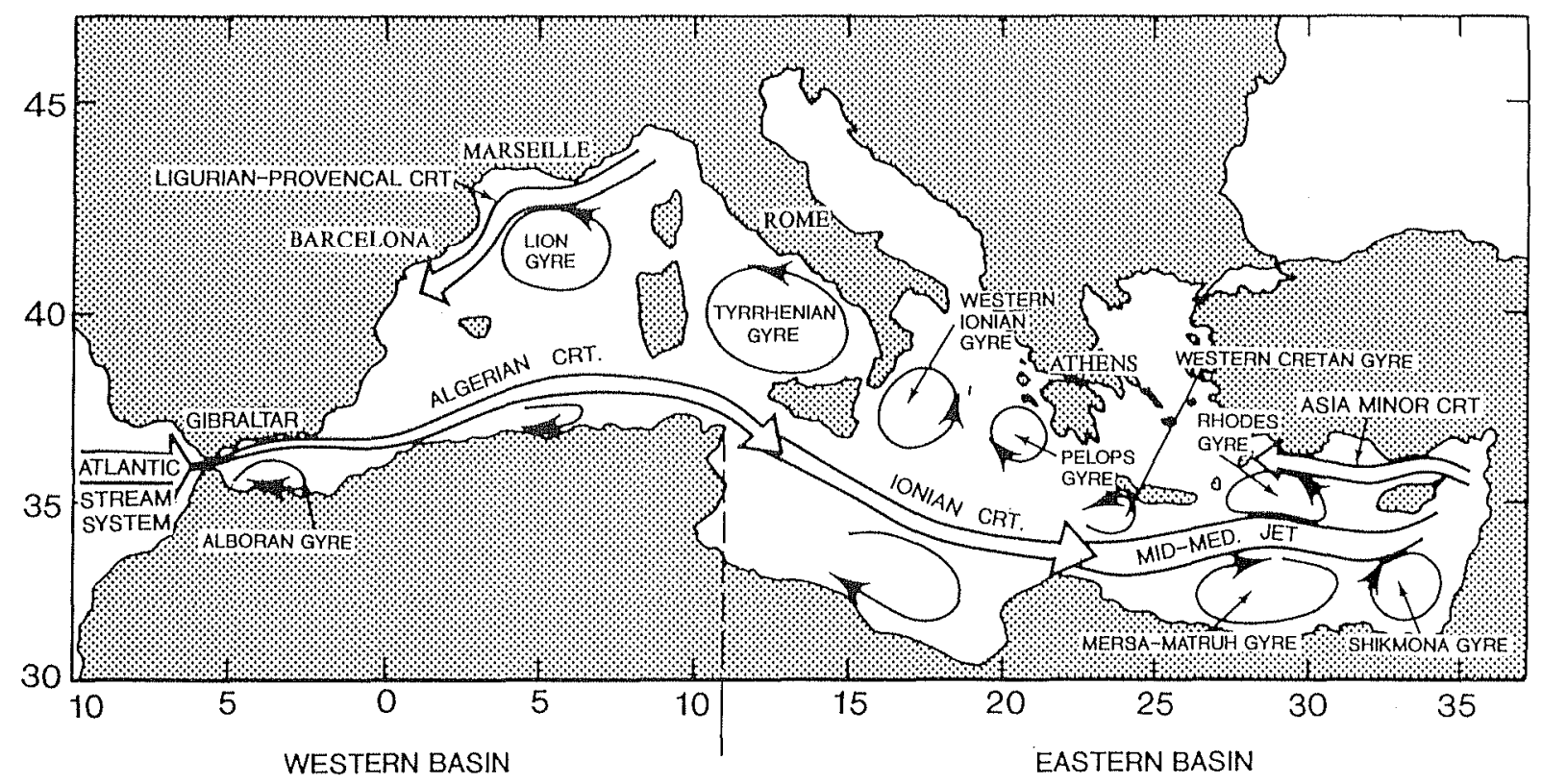

Figure 1. Features and currents in the Mediterranean Sea [from Roussenov et al., 1995].

Mersa-Matruh and Shikmona gyres to the south [Robinson et al., 1991]. The seasonal and interannual variability of the circulation is thought to be mainly due to atmospheric forcing (wind stress, heat flux), although changes in inflow/outflow at Gibraltar should also be taken into account [e.g., Roussenovet al., 1995]. The variability of the general Mediterranean Sea circulation is, however, mainly inferred from modeling results [e.g., Pinardi and Navarra, 1993], and observational evidence is still lacking.

To date, the Mediterranean oceanic circulation literature does not contain any account of global description by satellite altimetry. This is because extracting the oceanic signal from altimeter data in the Mediterranean is particularly difficult. The first reason is that the topography signal is small, of the order of $10 \mathrm{~cm}$ at most. Then, the geometry (narrowness, straits, islands) of the basin is complex; the orbit error cannot be as easily corrected for as in the open ocean, since classic techniques, such as bias and slope adjustment, would remove a large part of the oceanic signal [e.g., Le Traon ef al., 1991]. It is now believed that the very high accuracy of TOPEX/ POSEIDON (T/P) can cope with those two problems. In particular, the $\mathrm{T} / \mathrm{P}$ orbit error is very small ( $3 \mathrm{~cm} \mathrm{rms}$ ), alleviating the need for a specific correction. The third reason is that the tidal signal, which can exceed $15 \mathrm{~cm}$ in amplitude, had not previously been globally and precisely modeled (P. Canceill et al., Barotropic tides in the Mediterranean Sea using a finite element numerical model, submitted to Joumal of Geop/tysical Research, 1994 (hereinalter referred to as submitted manuscript)). The solution of the new hydrodynamic model agrees with tide gatuge data to within $2 \mathrm{~cm} r \mathrm{~ms}$ for the $\mathrm{M}_{2}$ component.

In this paper we use 2 years of T/P data in the Mediterranean with the new tidal correction. The data processing and influence of atmospheric pressure variations on the sea level are presented in section 2 . In section 3 we discuss the temporal changes of the mean sea level observed by T/P. Finally, we attempt in section 4 to show that the classic image of the Mediterranean surface circulation and some new features emerge from altimetric data analysis. Since altimetry provides continuous coverage, the transient or permanent character of features over the 2 years of the study can be elucidated.

\section{Data Processing and Atmospheric Pressure Forcing}

\subsection{Data Processing}

The T/P merged geophysical data record (GDR-M) from the first 2 years was used for this study (Figure 2). The record spans the period between October 4, 1992 (cycle 2), and September 15, 1994 (cycle 75), i.e., a total of 74 ten-day cycles. The Centre National d'Eltudes Spatiales (CNES) Joint Gravity Model 2 (JGM-2) precise orbit was used, and the following corrections were used [see Le Traon et al., 1994]: TOPEX/ POSEIDON microwave radiometer for the wet troposphere; European Centre for Medium-Range Weather Forecasts (ECMWF) for the dry troposphere and inverse barometer effect; 300-km, low-pass-filtered bifrequency ionospheric correction for TOPEX; Doppler orbitography and radiopositioning integrated by satellite (DORIS) ionospheric correction for POSEIDON; electromagnetic bias correction using the so-called BM4 parameterization for both instruments [Gaspar et al., 1994]; Cartwright and Tayler [1971] solid tides; Ray and Sanchez [1989] ticlal loading; and Canceill et al. (submitted manuscript, 1994) ocean tides.

Along-track corrected sea surface heights were resampled every $7 \mathrm{~km}$ using cubic splines, and sea level anomaly (SLA) measurements were obtained by removing the 2-year mean. To reduce the altimetric noise, SLA data were finally low-pass filtered using a $35-\mathrm{km}$ median filter and a Lanczos filter with a cutoff wavelength of $42 \mathrm{~km}$.

\subsection{Inverse Barometer Correction}

In the open ocean the response to atmospheric pressure is close to the well-known inverse barometer (IB) effect [e.g, Fut and Pihos, 1994]. The IB correction (IBC) is simply given by

$$
\mathrm{IBC}=1 / \rho g\left(P-P_{\mathrm{ICI}}\right)
$$




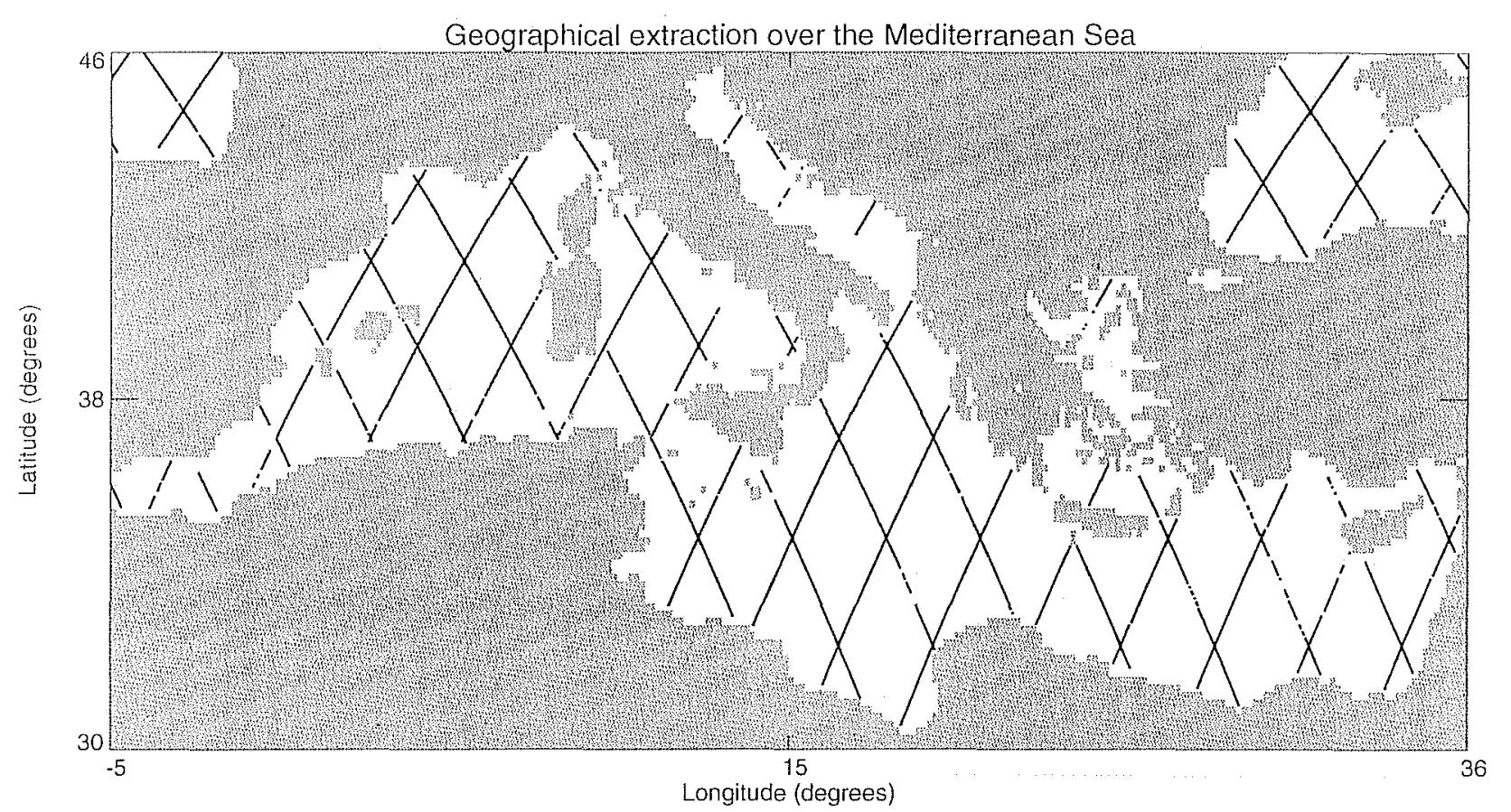

Figure 2. Location of TOPEX/POSEIDON tracks in the Mediterranean Sea.

where $P_{\text {rur }}$ is the mean pressure over the ocean which, in practice, is generally assumed to be constant. Following (1), a 1-mbar variation in atmospheric pressure yields a sea level variation of $1 \mathrm{~cm}$. In a closed basin, because mass must be conserved, $P_{\text {rel }}$ must be made equal to the mean pressure over the basin; thus only local adjustment to spatial variations of the pressure occurs. In a semienclosed sea, such as the Mediterranean, the response is more complex. The sea level can respond to the mean pressure over the basin if there is an adjustment through the straits. With the work of Lacombe [1961] and Crépon [1965] it has been recognized that this adjustment occurs. Crépon [1965] observed al correlation between the flux through Gibraltar and the mean atmospheric pressure. Actually, the continuity equation implies a correlation with the time derivative of pressure, not pressure itself. Several papers have dealt with the problem [e.g., Garretl and Majaess, 1984]. Candela [1991] has more recently proposed a simple model which takes into account the friction at the Gibraltar and Sicily Straits. His model provides a response of sea level produced by an input spectrum of atmospheric pressure. At low frequencies the straits do not constrain the flow. At high frequencies the Mediterranean cannot fully adjust, and the response differs from a simple IB effect. As a consequence, pure correlation with pressure changes cannot be expected.

Our ultimate goal was to correct the altimetric measurements from atmospheric pressure effects. However, since the subject of ocean response to pressure is particularly interesting, we will comment on the consequences of our allempls to go beyond simple processing. We first assumed that the Mediteranean Sea was acting as a closed basin and applied an IB correction with a reference pressure $P_{\text {rer }}$ equal to the mean daily pressure over the Mediterranean basin. The rms SLA increased lirom $9.2 \mathrm{~cm}$ using a constant (1013 mbar) reference pressure (standard IB correction) 10 about $11.5 \mathrm{~cm}$ rms. This confirms that there is an adjustment through the strats. Regression analysis between sea level and atmospheric pressure was then performed to better characterize the response of the Mediterranean Sea to atmospheric pressure. An SLA file without IB correction was generated, and correlation between SLA and instantaneous pressure was calculated. To reduce the infuence of low-frequency oceanic signals in the regression, SLA data were converted to 10-day differences (differences between two consecutive cycles). The mean correlation of the sea level with atmospheric pressure was found to be as significant as -0.6 . The regression coefficient was $-0.88 \mathrm{~cm} \mathrm{mbar}^{-1} \pm 0.30$ $\mathrm{cm} \mathrm{mbar}^{-1}$, which is very similar to the results obtained by $F u$ and Pihos [1994] in the open ocean. Note that a regression with SLA data relative to a mean (instead of 10-day differences) yields a larger regression coefficient of $-1.13 \mathrm{~cm} \mathrm{mbar}^{-1}$ because low-frequency oceanic signals due to winds and heat fluxes are also correlated with the atmospheric pressure.

This analysis does show that in first approximation the response of the Mediterranean Sea to atmospheric pressure is close to a standard $\mathrm{BB}$ effect. The $\mathrm{IB}$ signal is actually as large as the remaining oceanic signals; the SLA valiance explained by a standard $I B$ correction is approximately $50 \mathrm{~cm}^{2}$, while the SLA variance signal is about $80 \mathrm{~cm}^{2}$ (see section 4). However, as shown by Candela [1991] and recalled in the discussion above, the response is certainly more complex and differs, in particular, from a standard IB effect at high frequencies. Better parameterizations will probably be developed in the future based on analytical models [e.g., Candela, 1991] or numerical models [e.g., Candela and Lozano, 1994].

We have chosen to apply a standard IB effect, although there is evidence that significant errors can occur for high-frequency atmospheric pressure lorcing. In particular, a few tracks show a mean sea level with $O(10 \mathrm{~cm})$ anomalies which are probably related to that kind of error. This needs to be corrected before any two-dimensional mapping of the data. A method was thus developed to correct these tracks for bials. The method is described in detail in the appendix. The bias is estimated iteratively from neighboring tracks in space and time. Only a few 

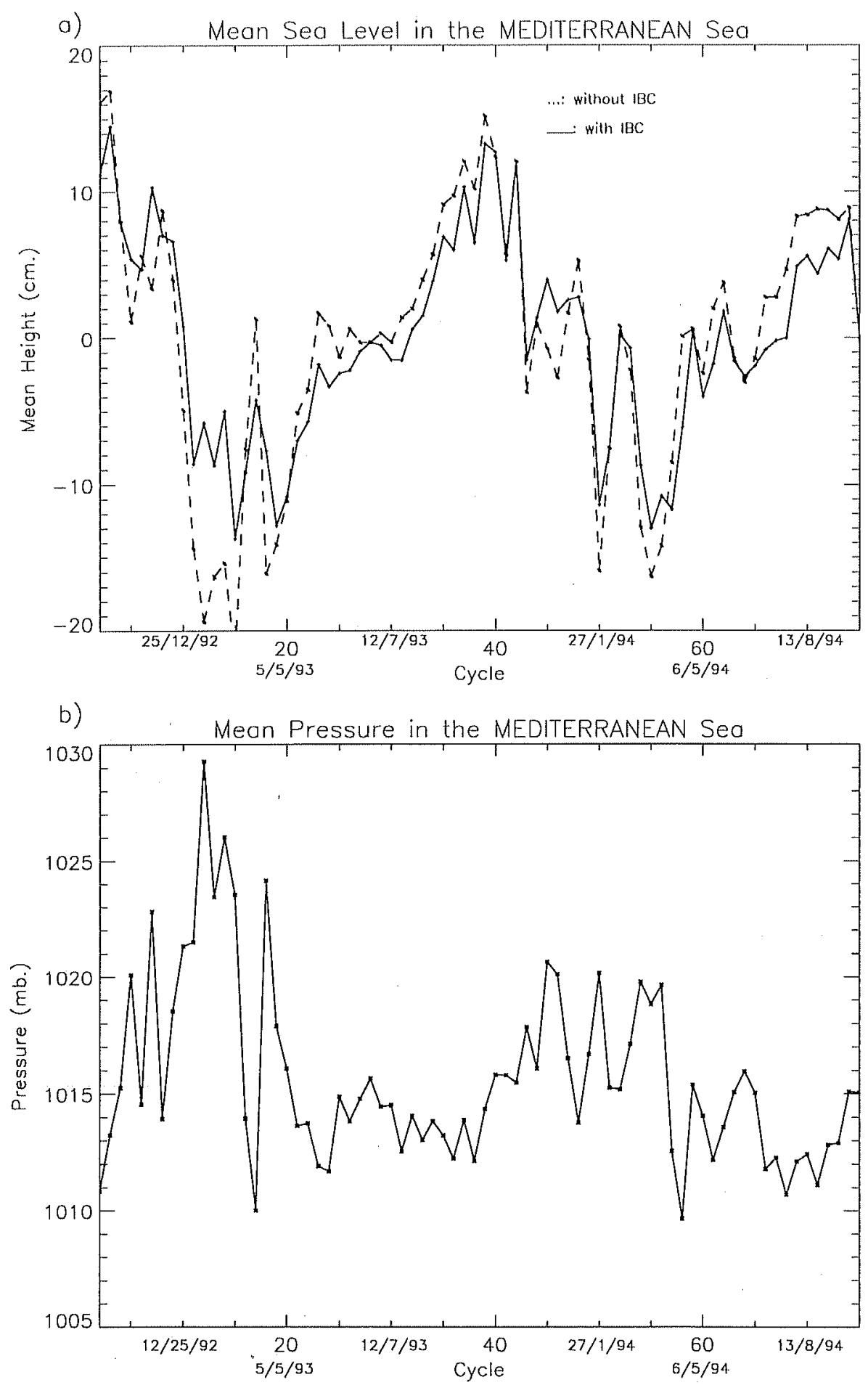

Figure 3. (a) Mean sea level in the Mediterranean Sea as a function of time, with and without inverse barometer correction (IBC). Units are centimeters. (b) Mean pressure as a function of time. Units are millibars.

tracks are adjusted, and globally, the correction is only $3.5 \mathrm{~cm}$ rms. The correction does not change the mean sea level estimations.

\section{Mean Sea Level Variations}

The discussion in section 2 confirms that there is an adjustment through the Gibraltar and Sicily Straits in response to the mean pressure and that the Mediterranean mean sea level is sensitive to the mean pressure. Figure 3a shows the mean sea level with and without the IB correction. The mean pressure over the Mediterranean is shown in Figure 3b. The influence of the mean pressure on the mean level is plainly seen. An IB correction should be applied to the mean sea level to study other effects. It is probably not very accurate, however, when atmospheric pressure varies rapidly (for example, here between cycles 17 and 18, March 1993).

The mean sea level over the whole Mediterranean and for 


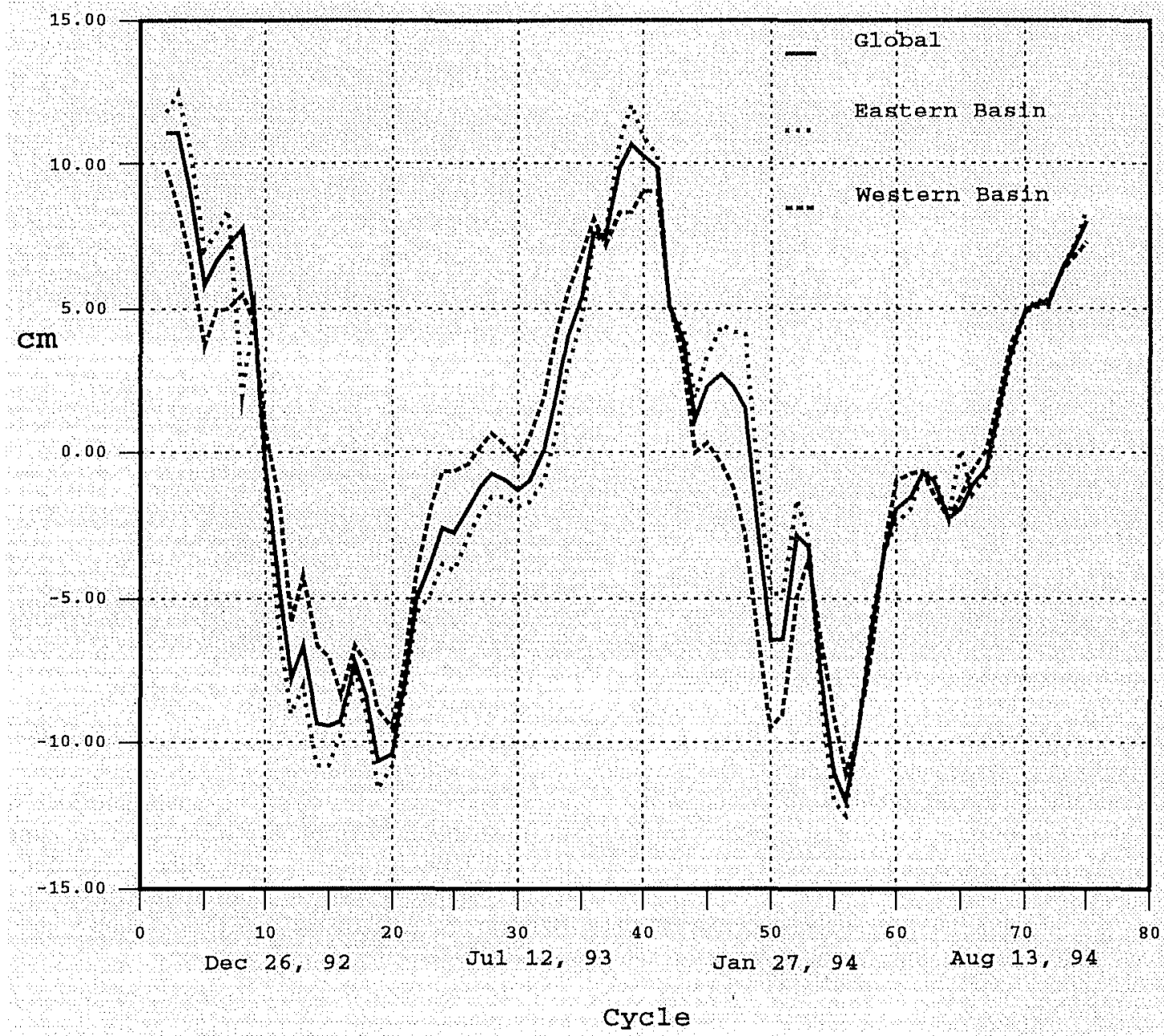

Figure 4. Mean sea level as a function of time for the whole Mediterranean Sea and the western and eastern basins. Units are centimeters.

the western and eastern basins is shown in Figure 4 . Note that Figure 4, contrary to Figure 3a, has been smoothed over three cycles. There is a clear seasonal signal, with an amplitude larger than $20 \mathrm{~cm}$. The sea level is highest in October, then decreases rapidly until March, then rises again but more slowly. The 2 years are not fully alike. In particular, the fast variations of the mean sea level during the 1993-1994 winter, up to $10 \mathrm{~cm}$ in amplitude, are not related to atmospheric pressure (see Figure 3b). The western and eastern basins show about the same variations but with a phase lag which varies with time.

Part of the mean level variations are attributable to a steric signal related to the dilatation and contraction of the surface layer due to heat fluxes. This eflect is given by [e.g., Gill and Niiler, 1973]:

$$
\frac{\partial \eta}{\partial t}=\frac{\alpha}{\rho C p} Q
$$

where is $\eta$ the sea level, $\alpha$ is the coefficient of thermal expansion, $C p$ is the specific heat at constant pressure, and $Q$ is the net heat fux. We calculated the steric signal using an ECMWF climatology of net heat fluxes (B. Barnier, personal communication, 1994). We obtain a signal of less than $10 \mathrm{~cm}$ which is maximum in October and minimum in March. We also used a seasonal climatology of the Mediterranean Sea [Brasseur et al., 1995] and general circulation model (GCM) results to estimate the dynamic height relative to $500 \mathrm{dbar}$. All three calculations give similar results.

As a consequence, "climatological" steric effects only appear to account for half of the observed variation of the mean sea level in 1993-1994, although the phase seens to be right. Of course, 1993 and 1994 may be untypical of the climatology. However, the mean T/P signal has the same amplitude in the 2 years, and large interannual variations are not expected. This suggests that the Mediterranean Sea may not be in mass balance at the seasonal timescale. It is interesting to note that a similar conclusion was reached by Ovchimnikov [1974] in his analysis of the water balance of the Mediterranean Sea. The mean sea level variations reported in his paper are close to our results. He suggested that fuctuations in water inflow and outflow through the Straits of Gibraltar are always of opposite signs. This induces a net barotropic flow which is not compensated by loss of water due to evaporation or gain due to precipitation and river runofl. As a consequence, mean sea level variations are induced. A net barotropic flow of $0.1 \mathrm{~Sv}$ in a month will produce an elevation of the mean sea level of 10 $\mathrm{cm}$. These hypotheses on the inflow/outflow at Gibraltar were not confirmed by flow measurements through the Straits of: 
Gibraltar during the Gibraltar Experiment [e.g., Biyden and Pillsbury, 1990). While small variations in the difference of inflow and outflow may well be responsible for the observed mean sea level variations, the causes of these variations are still to be understood.

The reservoir condition which determines the exchange at seasonal scales through the straits and ultimately the mean sea level is evaporation minus precipitation $(\mathrm{E}-\mathrm{P})$ [e.g., Bryden and Kinder, 199/b). The seasonal variations in E-Pare poorly known in the Mediterranean Sea. It is thought, however, that $E-P$ is maximum in summer, although there are periods of intense evaporation in winter [Harzallah et al., 1993]. This disagrees with the phase in our observations. However, the response to the winter evaporation conditions during the convective formation of deep waters and Levantine Intermediate Water, where strong vertical mixing takes place, is probably stronger and slower, since it is baroclinic. The barotropic adjustment to $\mathrm{E}-\mathrm{P}$ will be quasi-instantancous, since gravity waves take less than a day to cross the basin (see also the discussion on the inverse barometer effect), and no signature on the mean sea level is expected. Internal hydraulic control in the Straits of Gibraltar should also be taken into account, since it imposes constraints on the baroclinic exchange [Bryden and Kinder, 1991b]. When the Strait of Gibraltar is in a maximal exchange condition, the mean sea level will directly respond to evaporation (although in the longer term the exchange conditions may be modified). During submaximal exchange, however, rapid adjustment through the straits is possible and no mean sea level signature is expected. The Stratts of Gibraltar may oscillate between maximal and submaximal exchanges [Garrett et al., 1990]. This could probably explain part of the signal observed.

We thus suggest that the Mediterranean sea level variations, apart from the steric effect, may result from baroclinic adjustment to $E-P$ variations. Explaining the Mediterranean mean level variations is, however, still an open and interesting issue, and many questions remain on the subject of Gibraltar Straits dynamics [Bryden and Kinder, 1991a].

\section{Seasonal Variations of the Surface Circulation in the Mediterranean Sea}

\section{1. - Statistical Results}

Plate 1 shows a map of the overall mo SLA. The geostrophic velocity variance was also calculated (Plate 2). The rms SLA generally lies between 6 and $8 \mathrm{~cm}$. High values of velocity variance reveal intense mesoscale activity, whereas low values are attributable to large-scale variations. A large part of the rms variability is due to the annual cycle of the mean sea level which has an amplitude of $O(10 \mathrm{~cm}$ ) (see section 3). This explains the relatively high background values found in some of the quietest subbasins, such as the Tyrihenian.

The largest $\mathrm{mms}$ signal in the western basin (larger than 12 $\mathrm{cm}$ ) is found in the Alboran Sea with its well-known energetic gyres. Patches of variability can be detected in the Algerian current eddies off the coast of Algeria. The mesoscale activity is even more obvious on the map of velocity variance. The Algerian current is unstable and generates mesoscale eddies that propagate eastward. Most of them are anticyclonic, located near the coast, with a size of about $50 \mathrm{~km}$ in diameter. With time, they leave the coast, grow to about $100 \mathrm{~km}$, and travel for several months in the interior of the Algerian basin with a velocity of a lew kilometers per day [Millo, 1990]. The eastern Tyrrhenian basin shows somewhat larger rms values than the west and, even more strikingly, than the neighboring Liguro-Provençal basin which is characterized by the lowest figures of the whole western basin. This suggests that this area has a variability mostly at the large scale [Millot, 1990], in contrast to the Alboran and Algerian basins discussed above.

In the eastern Mediterranean the rms SLA values are wher homogeneous over the Ionian basin and eastern Levantine basins, with a magnitude of about $7.5 \mathrm{~cm}$. Larger rms values along Tunisian and western Lybian coasts are observed (about $8.5 \mathrm{~cm}$ ). The region, however, is shallow, and the larger rms values may be due to errors in the tidal model or wind effects. This may also hold for the Adriatic and the Aegean Seas. The variability reaches a local but very well marked maximum of about $17 \mathrm{~cm} \mathrm{~ms}$ in a small area southeast of Crete. It is also atssociated with a peak of geostrophic velocity variance. This is the so-called Ierapetra gyre which we discuss later. Figure 6 (bottom) shows the variance of wind stress curl anomalies with respect to the annual mean. The analogy with Plate 1 is quite striking, since the three regions of maximum wind variance identified as V-E, VI-E, and VII-E in Figure 6 (bottom) coincide with regions of high sea level variability. We thus expect winds to play an important role in forcing the variable circulation there. Some of the low-rms areas of Plate 1 are regions where surveys and numerical simulations have shown the presence of permanent features. One can assume, for instance, that the relative variability minima $(6.5 \mathrm{~cm})$ in the southern Cretan Sea and in the northwestern Levantine basin are the signature of the rather permanent mid-Mediterranean jet and the Rhodes gyre, respectively.

\subsection{Synoptic and Seasonal Estimates of the Surface Circulation}

The 2-year T/P SLA were interpolated onto a regular $0.2^{\circ} \times$ $0.2^{\circ}$ grid by a suboptimal space-time objective analysis package (P. De Mey, personal communication, 1992) every 10 days starting October 4, 1992 (CNES Julian day 15617). The correlation function in the analysis was defined as

$$
\begin{aligned}
C(r, t)= & {\left[1+a r+\left(\frac{1}{6}\right)(a r)^{2}-\left(\frac{1}{6}\right)(a r)^{3}\right] } \\
& \cdot\left[\exp (-a r) \exp \left(\frac{-t^{2}}{T^{2}}\right)\right]
\end{aligned}
$$

where $T=15$ days and $a$ is such that $L=3.34 / a=150 \mathrm{~km}$ is the spatial zero crossing. Given the large spatial intertrack distance, the mapping error reaches up to $70 \%$ of the signal variance between the tracks. Only the large-scale features of the circulation can really be observed with T/P, and smallerscale signals will only be discussed when they are close to T/P tracks.

Three monthly seasonal averages were calculated, with winter beginning in January. The estimates relative to the 3-month spatial averages are presented in Plates 3 and 4 . The annual signal was also extracted by fast Fourier transform (FFT) analysis and mapped as described by Le Traon and Minster [1993] (Plates 5 and 6). Descriptions of the surface circulation per basin and subbasin follow.

Western basin as a whole. As the mean circulation in the WM sea is cyclonic [e.g., Millot, 1990], the negative anomaly observed by $\mathrm{T} / \mathrm{P}$ in winter (Plate 4 ) in the central part of WM basin implies an intensification of the circulation. Remember 

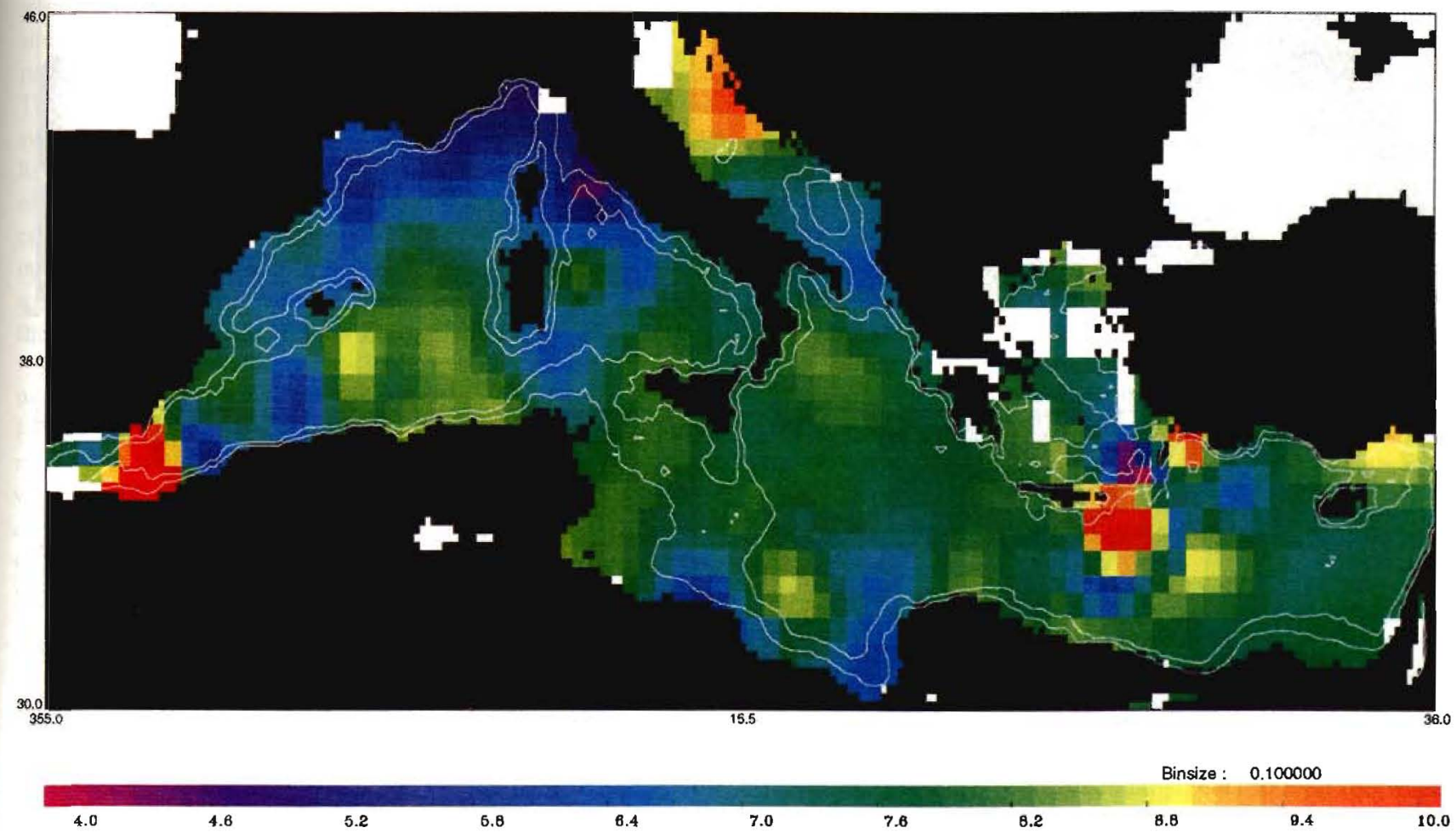

Plate 1. The rms sea level anomaly for cycles $2-75$. Units are centimeters.

that altimetric maps only give the variation relative to the mean circulation. Summer appears to be quiet, whereas fall and spring scem to be transition periods. One notes that the intensification of the circulation is less marked in 1993 than 1994 (Plates 3 and 4). Even if we find again a minimum of SLA in the center of WM sea, in winter it changes in magnitude, size, and form. Nevertheless, T/P annual signal (2 years) exhibits a maximum at the same location (Plate 5). It confirms that the cyclonic, basin-scale circulation in the western Mediterranean Sea is intensified in winter. Since the annual har-

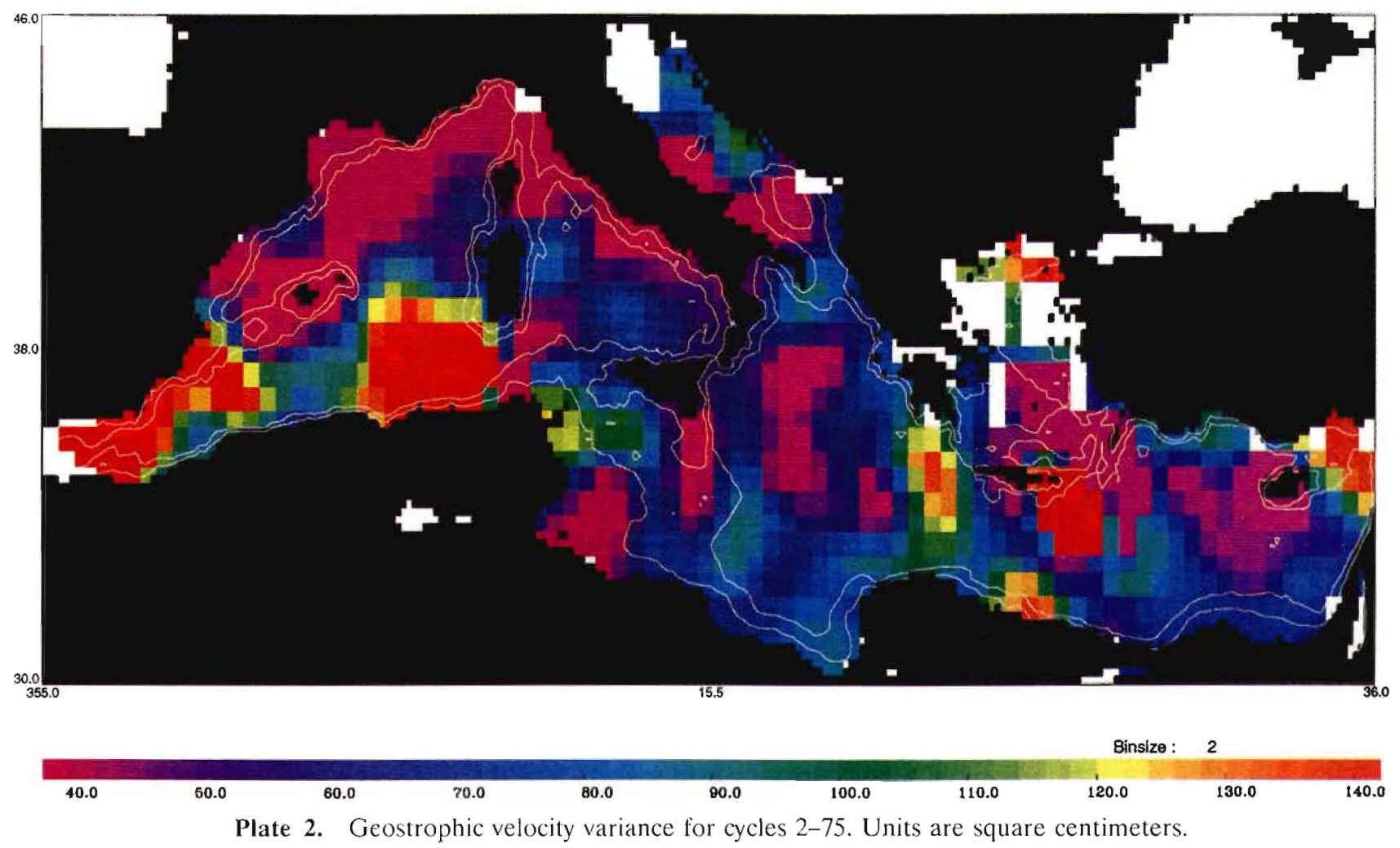



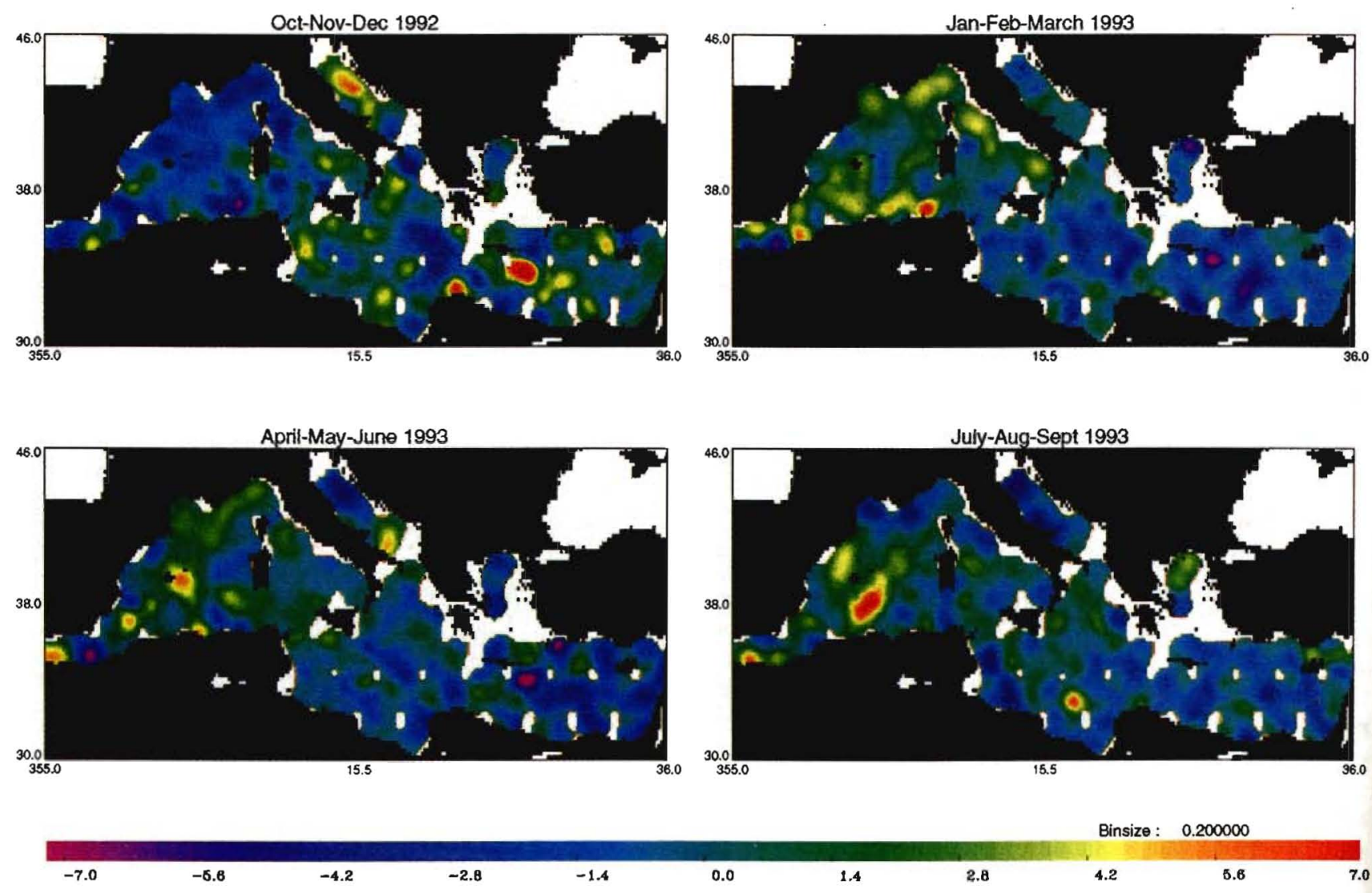

Plate 3. Seasonal sea level anomaly (SLA) averages for cycles $2-75$ in autumn 1992, winter 1993, spring 1993, and summer 1993. Units are centimeters. Spatial means of $8,-7,-3.8$, and $3 \mathrm{~cm}$, respectively, were removed for each map.
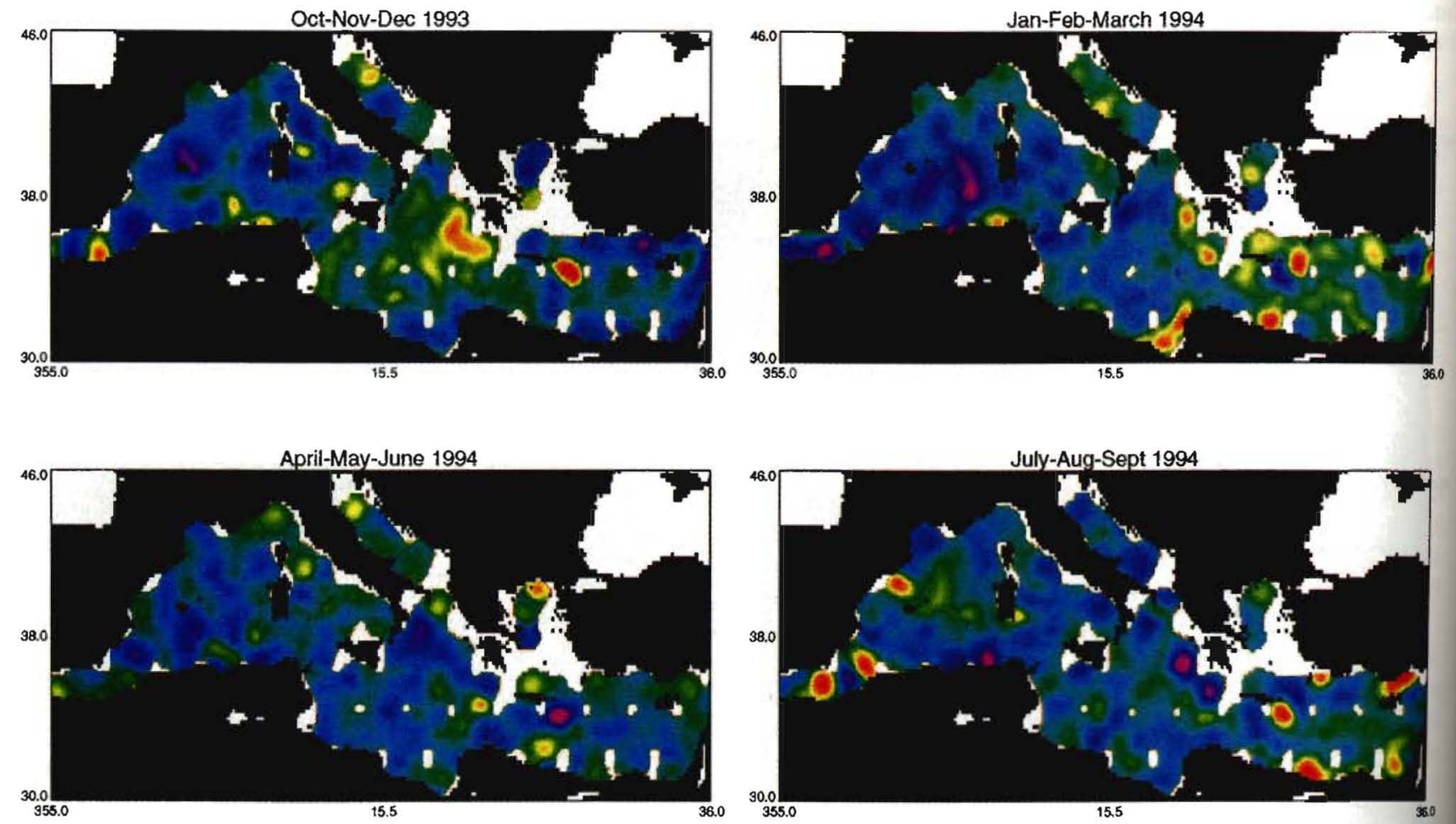

\begin{tabular}{lllllllllll} 
& \multicolumn{1}{c}{ Binsize : 0.200000} \\
\hline
\end{tabular}

Plate 4. Seasonal SLA averages for cycles 2-75 in autumn 1993, winter 1994, spring 1994, and summer 1994.

Units are centimeters. Spatial means of $6,-4.5,-3.6$, and $3 \mathrm{~cm}$, respectively, were removed for each map. 
monic wind stress curl amplitude map shows a maximum also situated in the center of WM (Figure 5), this intensification is probably related to the wind forcing and thermohaline flux. The major factor of the observed seasonal and interannual variability is thus probably the wind forcing and the thermohaline flux, although the variation of inflow through the Straits of Gibraltar could also affect the western circulation. Algerian eddies can be clearly detected by T/P (see, for example, the map on CNES Julian day 15710 shown in Plate 7), but the space-time sampling of T/P is not dense enough to follow them, and we will not discuss them further.

Alboran gyres. The Alboran Sea is a transition area between the straits of Gibraltar and the Almeria-Oran front $\left(-5^{\circ} \mathrm{W}-0^{\circ}\right)$ [Tintore et al., 1988]. The surface flow in the Alboran Sea is mainly composed of two anticyclonic gyres, named western (WAG) and eastern Alboran gyres (EAG) [Tintoré et al., 1988; Hebum and La Violette, 1990]. They are clearly detected on the T/P seasonal maps (Plates 3 and 4). The EAG gyre is found near $2^{\circ} \mathrm{W}$ over the 2 years. Its stability is presumably correlated to the Almeria-Oran front space stationarity [Tintore et al., 1988]. The WAG location is between $5^{\circ} \mathrm{W}$ and $4^{\circ} \mathrm{W}$. The EAG and, to a less extent, the WAG are both characterized by a strong temporal variability. We list in Table 1 their evolution from October 1992 to October 1994. Since the two gyres are anticyclonic, there are seen as cyclonic gyres with $\mathrm{T} / \mathrm{P}$ when they have their minimal amplitude. EAG is maxinum in summer and autumn, whereas WAG is maximum in spring and summer. The two gyres also exhibit smallertimescale variability. As explained by Speich et al. [1995], it seems that there is no well-defined law that would govern their appearances, and their evolutions seem to follow independent paths. However, the 2-year results in Table 1 show a surprising similarity in the behavior of each gyre from one year to the next. Therefore their long-term variations are possibly driven by seasonal mechanisms, such as Gibraltar inflow/outflow or wind stress changes.

Liguro-Provençal current and Tyrrhenian gyre. T/P seasonal maps (Plates 3 and 4) show significant seasonal variability in the Ligurian basin and in the northern Tyrrhenean basin. This variability is situated along the Ligurian coast, whereas the northern zone of Corsica seems to be nore stable. It is clear that we cannot detect the Liguro-Provencal current with good accuracy with the coverage of $\mathrm{T} / \mathrm{P}$ data due to its small width (of the order of $30 \mathrm{~km}$ ), but there is some evidence of a winter intensification of the neighboring region of LiguroProvençal current (particularly in winter 1993) and of the Tyrrhenean current along the coast of ttaly. The Liguro-Provençal current is actually composed of the eastern and western Corsica currents, but its variations are mainly induced by the eastern Corsica current which is fed by the Tyrrhenean current [Astraldi ef al., 1994]. The variations of the two currents are thus expected to be correlated. The winter intensification is also expected, since the winter transport in the Straits of Corsica is estimated to be about 3 limes larger than the summer one (1.5 versus $0.45 \mathrm{~Sv}$ ) [Astraldi et al., 1994]. In 1994 the winter and attumn circulation in the whole Tyrrhenean Sea is a well-defined cyclonic flow. This description of Tyrrhenean circulation agrees well globally with the circulation given by Krisvoheva and Ovchinikov [1973]. The wind stress curl peak (V $-W$ ) in the center of the Tyrrhenean basin (figure 5) may well explain the cyclonic circulation seen by T/P data in 1994 .

Eastern basin as a whole. The eastern Mediterranean circulation is characterized by a large range of spatial and tem- poral scales, and the combination of the various scales results in a more complex pattern than in the western Mediterranean. In the previous studies some mesoscale or large-scale features have been found to be present all over the year (like the cyclonic Rhodes gyrc), whereas others are transient (e.g., eddies in the southern Levantine basin) [Robinson et al., 1991; Özsoy et al., 1993]. Numerical simulations [Tziperman and Malanotte-Rizzoli, 1991; Roussenov et al., 1995] have shown that some of these features have seasonal variations. However, some uncertainties remain about the persistent or transient characteristics of these features. In this respect, the continuity and repetitivity of altimetric data should be very helpful.

N. Pinardi et al. (submitted manuscript, 1994) have simulated the Mediterranean circulation forced by realistic winds and heat fluxes from January 1980 to November 1988 and show that interannual variations appear because of the atmospheric variability. These variations are found to be the strongest in the eastern Mediterranean, where they can exceed the seasonal cycle. This study also hints at the importance of heat fluxes in forcing the Levantine basin circulation (see also Roussenov et al. [1995]. Plates 3 and 4 indeed show that the surface circulation is quite different from one year to the next. The structures change their shape, location, and intensity and can even show a reversed signature with respect to the mean. We thus expect the presence of interannual signals to hide the weaker seasonal cycle.

Ionian basin. The main tendency is an overall cyclonic circulation in the basin in winter (Plates 3 and 4). The southern branch of this circulation can be assimilated to the Ionian current which links the western and eastern Mediterranean basins. In the other seasons the southern Ionian basin shows a more complicated circulation pattern, with the occurrence of numerous transient gyres. These signals probably represent the Ionian current variability; during summer the current is thought to move northward as a consequence of the annual wind stress curl variations and to meander [Tziperman and Malanotte-Rizzoli, 1991; Pinardi and Navarra, 1993]. Figure 6 shows that the strongest wind stress curl variability occurs in the Ionian basin, where the differences reach 5-10 $\mathrm{dyn}^{-3} \mathrm{~cm}^{-3}$ from winter to fall and from spring to winter. Therefore the onset of a cyclonic gyre in the Ionian basin in winter could be the response to the positive wind stress curl. According to Pinardi and Navara [1993], local wind changes make up about $70 \%$ of the amplitude of the Ionian circulation variability. The remaining $30 \%$ is induced by remote forcing from the Levantine basin. They also conclude that the southern Ionian basin is more sensitive to the remote forcing than the northern one.

Plate 4 shows a circulation pattern reversal in the northwestern Ionian basin; the signal is anticyclonic in OctoberDecember 1993 and then cyclonic during the other seasons. The low first appears southeast of Sicily at the end of December; it intensifies and extends northward along the Sicilian and Calabrian coasts during winter. It reaches its maximum in extension and amplitude in March, occupying all the northern Ionian basin. From Plate 4 the negative sea level anomaly seens to propagate northward from east of Sicily in January to the Calabrian coast in August. Plate 6 shows the existence of different successive stages in the region; the annual signal amplitude is $6 \mathrm{~cm}$ in September at about $38^{\circ} \mathrm{E}-16.5^{\circ} \mathrm{S}$ and less than $5 \mathrm{~cm}$ in the north and is the other way around in January. The annual amplitude of the wind stress curl reaches a maximum amplitude there (Figure 6). The cyclonic gyre found in the northwestern Ionian basin (the "westem Ionian gyre," in ref- 


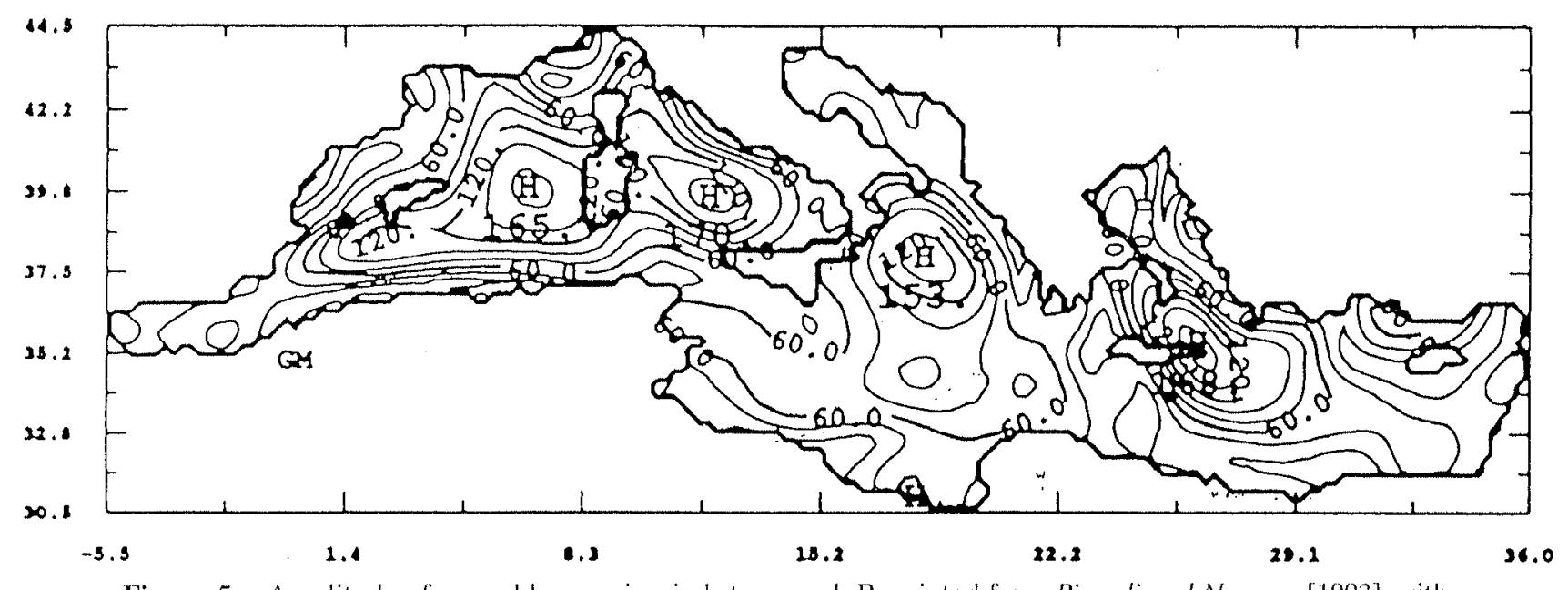

Figure 5. Amplitude of annual harmonic wind stress curl. Reprinted from Pinardi and Navara [1993], with kind permission from Elsevier Science Ltd., The Boulevard, Langford Lane, Kidlington, OX5 IGB, United

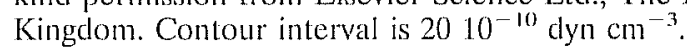

erence to Figure 1) is thus characterized by an intensification in winter due to an increasing positive wind stress curl and by a phase decay in its seasonal variations between its nothern and southern parts.

In the eastern Ionian basin, along Peloponnisos coast, twin structures undergo large changes between summer and winter. Their location matches the location of the Pelops gyre mentioned by Theocharis et al. [1993] in their analysis of POEMII-86 and POEM-V-87 data. They describe that gyre as an anticyclonic and persistent feature which can appear as having two centers. Roussenov et al. [1995] have simulated, in that region, a seasonal circulation reversal giving rise to a recurrent anticyclonic gyre. Our data do not allow us to discuss the persistence of the Pelops gyre throughout the year, but we clearly observe an intensification of the anticyclonic signal during winter 1994 and a weakening in summer 1994. In the previous year, sea level undergoes slight variations in this region, and we are unable to ascertain a cyclonic or anticyclonic tendency.

The Levantine basin. The overall circulation in the Levantine basin is anticyclonic in October-December and cyclonic in April-June (with respect to the mean) (Plates 3 and 4). Circulation patterns show, however, a strong variability between 1993 and 1994, with more dramatic changes than in the other basins. The greatest differences are observed between winter 1993 and winter 1994, with the occurrence of gyres of opposite signs (Plates 3 and 4).

A very energetic gyre, southeast of Crete, is the only feature whose annual cycle is repeated over the 2 years. It is well defined in T/P data because it stands at a crossover point. Its amplitude undergoes strong annual variations (more than 25 $\mathrm{cm}$ ), whereas its position is stationary (its apparent diameter is about $100 \mathrm{~km})$. It reaches its maximum intensity in late summer (September-October), then weakens to a minimum in spring. The signal almost disappears in June and July. This strong structure appears in the POEM data of AugustSeptember 1987 and March 1989 surveys [Robinson et al., 1991; Ozsöy et al., 1993; Theocharis et al., 1993]. Called the "Ierapetra anticyclone," it is described as a permanent feature. Its intensification in summer is responsible for the strongest surface signature in T/P data in the eastern Mediterranean. It has also been observed on IR images in September 1987 and August
1990 and in airborne expendable bathythermograph (AXBT) data [Horton et al., 1994]. In both data sets a symmetrical, cyclonic eddy (although of smaller intensity) is seen southwest of Crete. This eddy cannot be observed by T/P because no tracks cross this region (see Figure 2). As the region is characterized by a high wind stress curl variance (Figure 6 , bottom), winds are expected to play an important role in forcing the circulation there. Horton et al. [1994] actually suggest that interactions between Cretean orography and the strong northerly winds (the Etesians) which blow during summer out of the Aegean Sea could generate this pair of cyclonic/anticyclonic eddies.

Some mesoscale structures are also observed; it has been difficult to link them with the "classic" gyres described in previous studies. We now document a few of them. The most frequent signal is an anticyclonic gyre off the Egyptian coast between $25^{\circ} \mathrm{E}$ and $30^{\circ} \mathrm{E}$. It appears with one or several centers which shift and undergo intensity variations. One could imagine this signal to be the Mersa-Matruh gyre signature. However, it does not present any seasonal cycle as the MersaMatruh gyre is generally assumed to do. The SLA map on day 16300 (mid-August 1994) shows some well-defined structures which can also be detected at several dates during summer (not shown). In the northern part a cyclonic feature is found about $30^{\circ} \mathrm{E}-36^{\circ} \mathrm{N}$ and is likely the signature of the Rhodes gyre. The anticyclonic feature in the Cilicia basin has been observed during the POEM surveys [Özsoy et al., 1993]. In the southern part, anticyclonic signals appear at about $28^{\circ} \mathrm{E}$ near the Egyptian coast and at about $33^{\circ} \mathrm{E}$ along the Israeli coast. In reference to previous studies, we can identify these features as the signatures of the Mersa-Matruh and Shikmona anticyclonic gyres, respectively. On CNES day 15710 (beginning of January 1993) the circulation pattern is quite different, with a predominant cyclonic central structure. In the Cretan Sea at $22^{\circ} E$ the meridional sea level gradient translates into eastward velocity anomaly relative to the mean. This "jet" then meanders in the southern Levantine basin and flows northward along the Israeli coast, westward south of Cyprus, and hugs an anticyclonic eddy in the Antalya basin and a cyclonic one in the Rhodes basin. Such a circulation is in good agreement with the classic ideas on the general circulation of the Levantine basin [e.g., Özsoy et al., 1993]. 


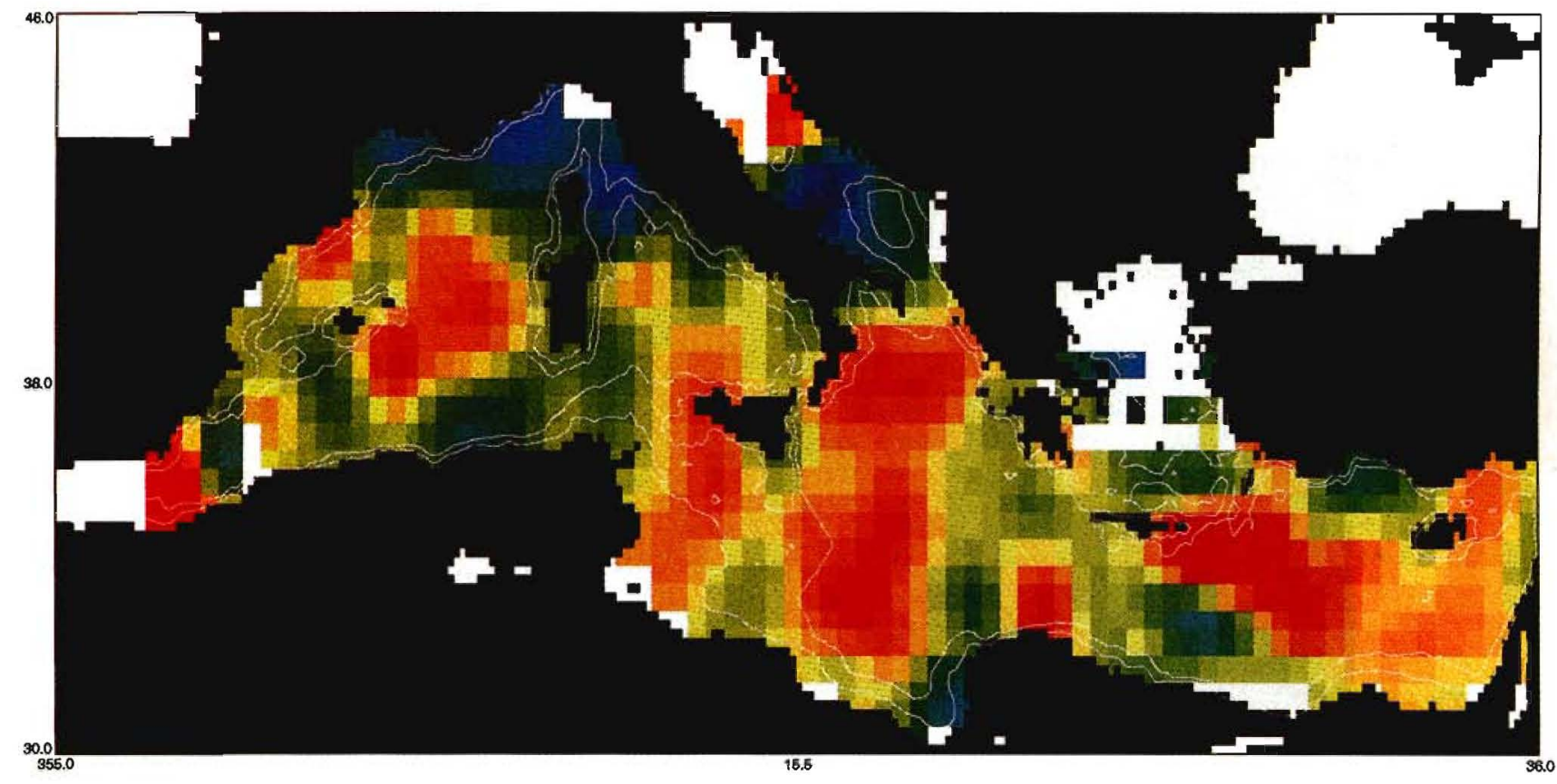

Binsize : 0.200000

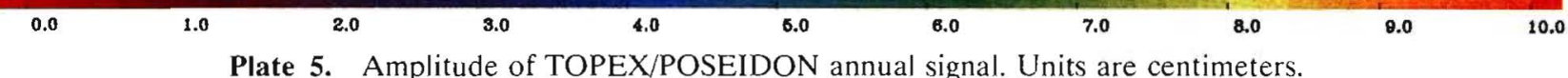

(a) August

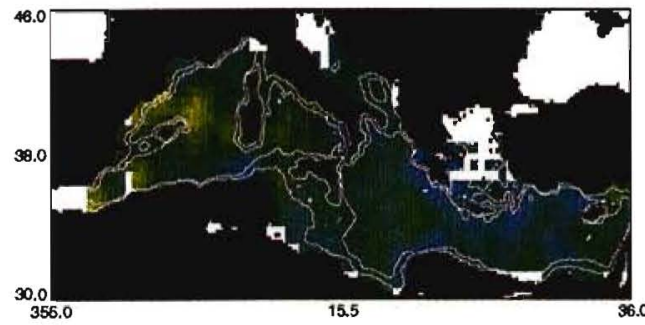

(c) October

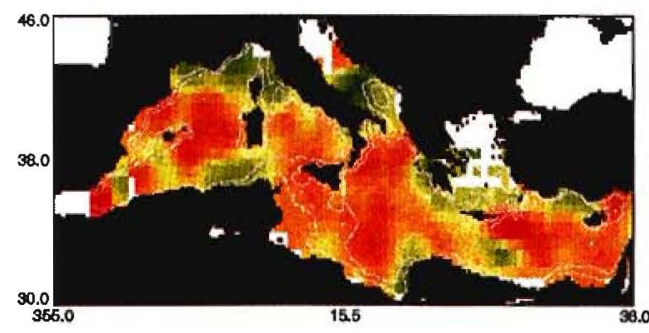

(e) December
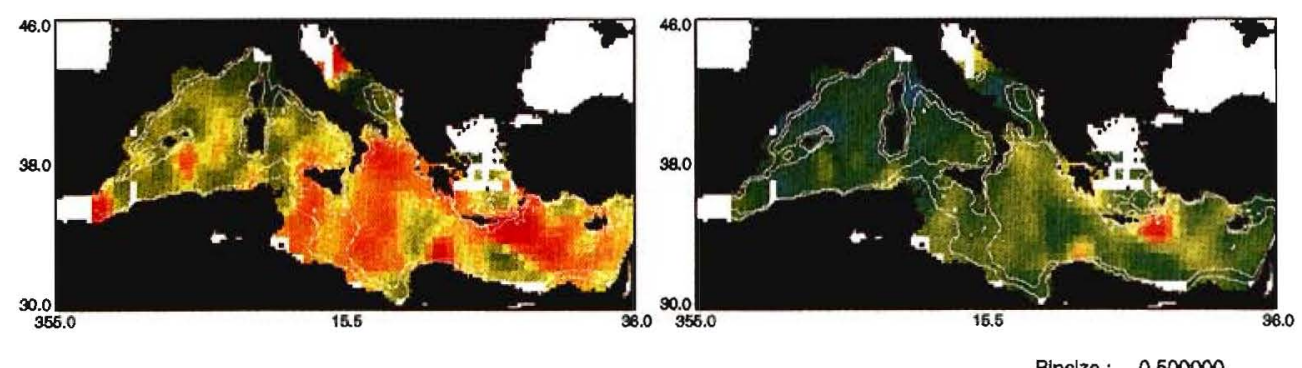

Binsize : $\quad 0.500000$

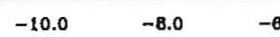

Plate 6. TOPEX/POSEIDON annual signal in (a) August, (b) September, (c) October, (d) November, (c) December, and (f) January. Units are centimeters.

(b) September

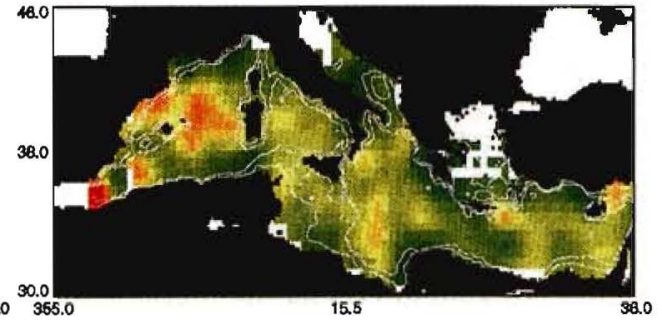

(d) November

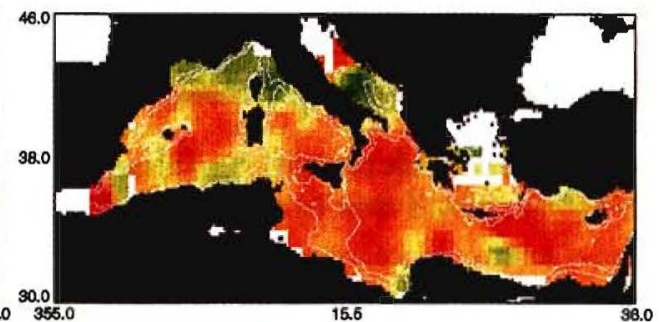

(f) January

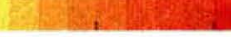


(a)

$\operatorname{Jan} 5,93$

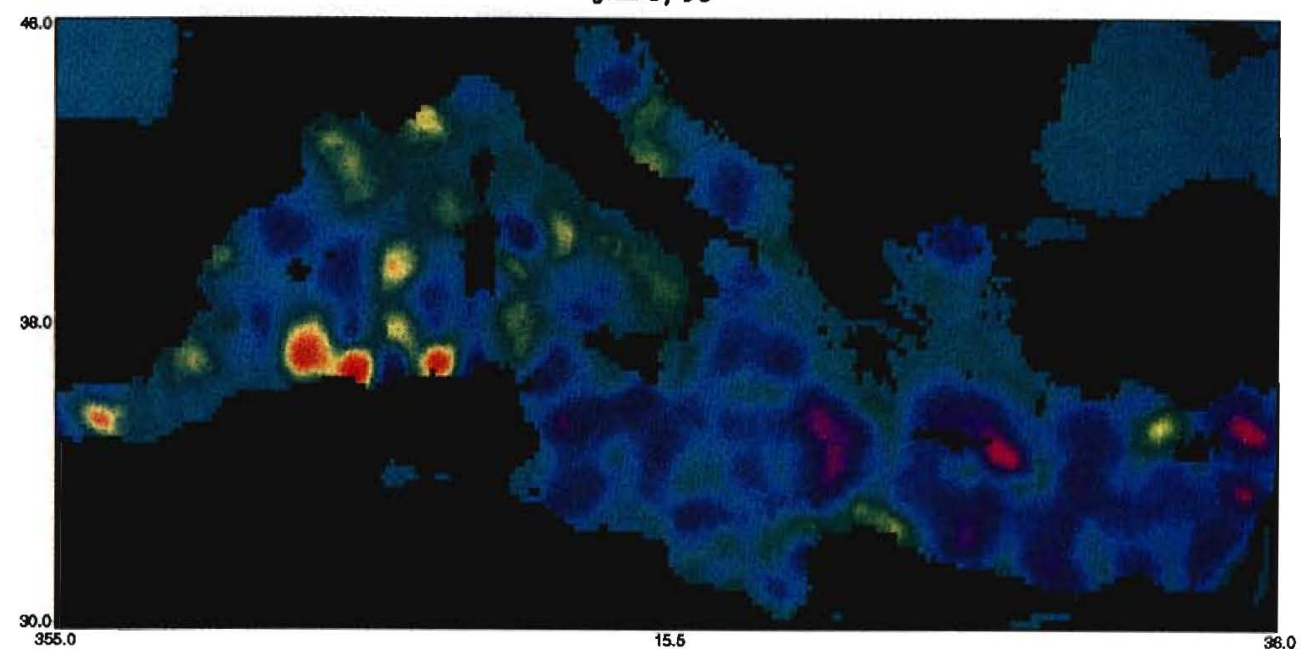

(b)

August 18,94

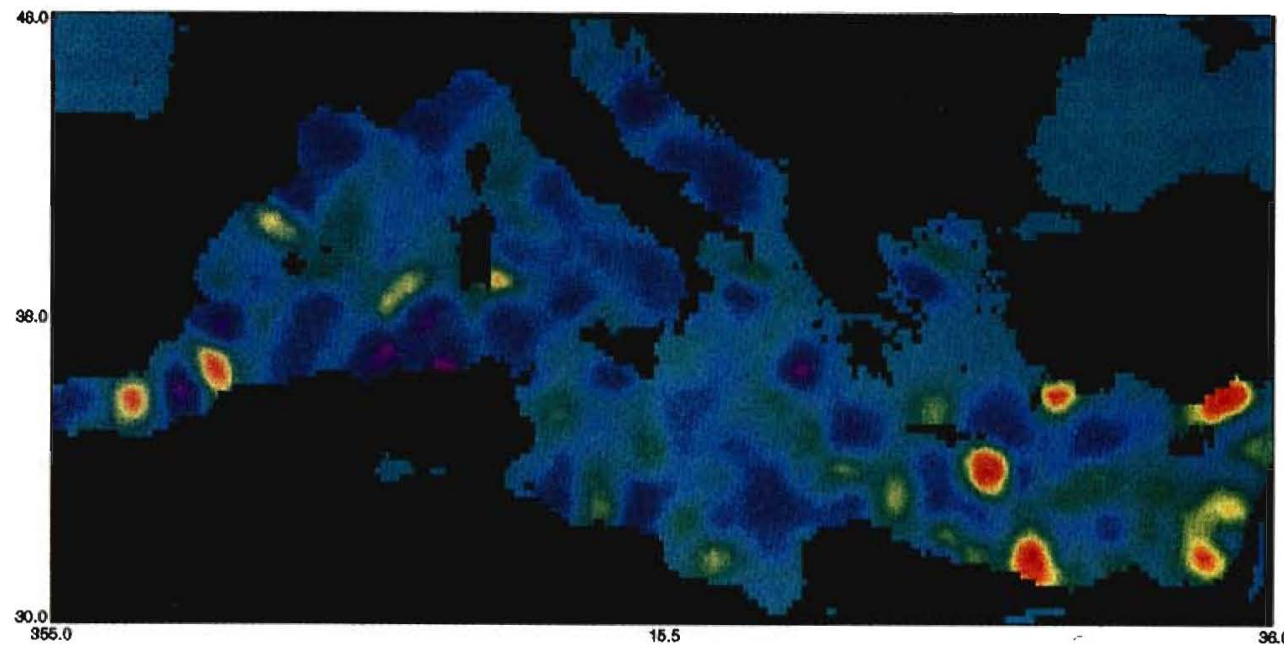

Binsize : $\quad 0.600000$

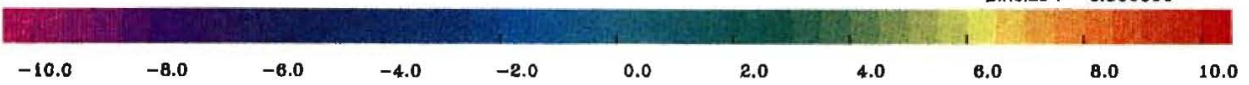

Plate 7. Sea level anomaly in the Mediterranean Sea calculated by objective analysis on (a) Julian day 15710 , January 5, 1993, and (b) Julian day 16300, August 18, 1994.

\section{Conclusions}

The Mediterranean mean sea level and circulation variations have been, for the first time, analyzed with altimetric data. Despite difficulties due to the low signal-to-noise ratio, results are very encouraging and demonstrate the high quality of $\mathrm{T} / \mathrm{P}$ data. Several interesting features of the Mediterranean Sea have been confirmed or revealed from T/P data. Our study first confirms that the Mediterranean Sea responds to atmospheric pressure as an inverted barometer (except at high frequencies) by an adjustment through the Straits of Gibraltar. The Mediterranean Sea mean sea level variations have been mapped for the first time, thanks to the very high accuracy of $\mathrm{T} / \mathrm{P}$ data. The

Table 1. Evolution of Alboran Sea Gyres

\begin{tabular}{|c|c|c|c|c|c|c|c|c|}
\hline & \multirow{2}{*}{$\begin{array}{c}1992 \\
\text { Autumn }\end{array}$} & \multicolumn{4}{|c|}{1993} & \multicolumn{3}{|c|}{1994} \\
\hline & & Winter & Spring & Summer & Autumn & Winter & Spring & Summer \\
\hline WAG & C & $\ldots$ & A & A & C & $\ldots$ & A & $\ldots$ \\
\hline EAG & A & C & C & A & A & C & $\cdots$ & A \\
\hline
\end{tabular}

WAG and EAG are western and eastern Alboran gyres, respectively. $\mathrm{A}$ is anticyclonic, $\mathrm{C}$ is cyclonic, and dots indicate absence of anticyclonic and cyclonic structure. 

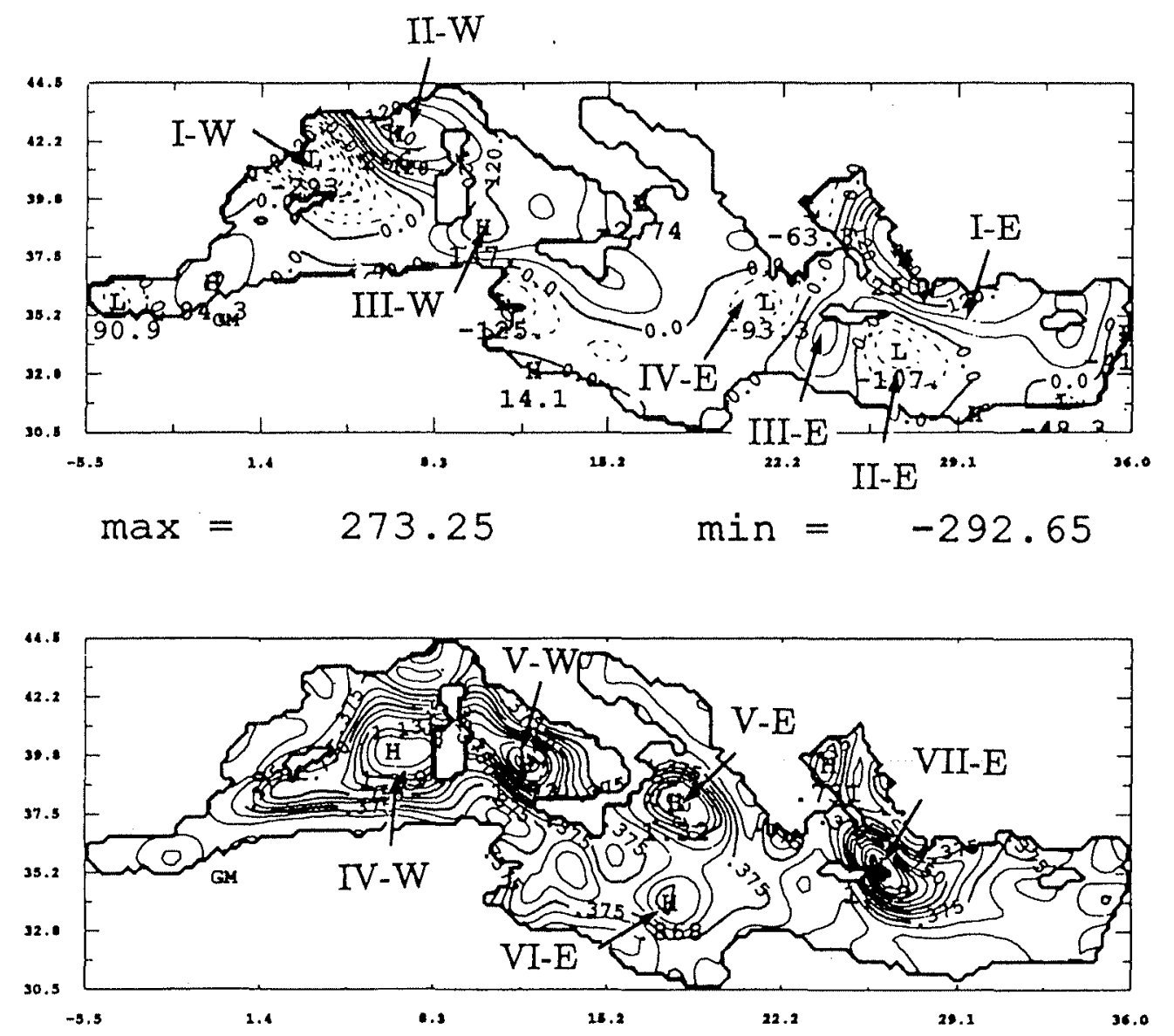

Figure 6. (top) Annual mean wind stress curl. (bottom) Variance of wind stress curl anomalies with respect to the annual mean. Units are $10^{-10} \mathrm{dyn} \mathrm{m}^{-3}$. Contour interval is $4010^{-10} \mathrm{dyn} \mathrm{cm}^{-3}$. Reprinted from Pinardi and Navara [1993], with kind permission from Elsevier Science 'Ltd., The Boulevard, Langford Lane, Kidlington $\mathrm{OX5} 1 \mathrm{~GB}$, United Kingdom.

mean sea level has variations of up to $25 \mathrm{~cm}$. It has an annual cycle with a fast drop during winter. Steric effects account for about half of the observed variations. The remaining signal is thought to be driven by evaporation minus precipitation forcing and internal hydraulic control in the Straits of Gibraltar. The issue is still open. A better understanding of the Gibraltar Straits dynamics and more accurate estimations of $\mathrm{E}-\mathrm{P}$ and heat fuxes variations are required. T/P data have also clearly evidenced the seasonal variations of the surface circulation. The large-scale cyclonic circulation appears thus to be more intense in winter and principally driven by wind stress curl variation. This is clearly detected for the Liguro-Provençal and Tyrrhenean basins, as well as for the Ionian. We also observed that the eastern circulation is more complicated than the western due to numerous subbasin-scale gyres and larger interannual varability. Strong anticyclonic mesoscale signals, such as the Alboran gyres or the Ierapetra gyre, were shown to have a clear scasonal variability, with a maximum in summer. MersaMatruh and Shikmona gyres have been also detected in the Levantine basin. They do not have, however, an obvious recurrence period and are characterized by rather short timescales.

Future work will deal with the comparison and combination of $\mathrm{T} / \mathrm{P}$ and ERS 1 altimeter data. This will provide a much denser coverage and will allow us to better follow mesoscale features. The altimetric data sets will then be assimilated in a general circulation model as part of the Mermaids project and should provide a very fine three-dimensional description of the Mediterranean Sea circulation.

\section{Appendix: Minimization of the Bias of a Track With Respect to the Background}

The inverted barometer correction is inadequate when pressure changes are fast because the Mediterranean Sea does not have time to adjust. An additional correction is therefore applied to individual tracks in the form of a bias. The algorithm minimizes the mean differences between a given track and the neighboring tracks in space and time. The differences are weighted by the length and the oceanic signal variance of each track.

The function to minimize is defined as

$$
\begin{aligned}
F= & \sum_{i}^{\text {lrack }}\left[\bar{h}(i, j)-a(i, j)-\mathrm{Niv}_{-} \operatorname{moy}(i, j)\right]^{2} \\
& \frac{[\operatorname{Var}(i)]^{-1}}{\operatorname{Np}(i, j)}+\sum_{i}^{\text {track }}\left[a^{2}(i, j)\right] \frac{1}{\sigma^{2}}
\end{aligned}
$$

where 


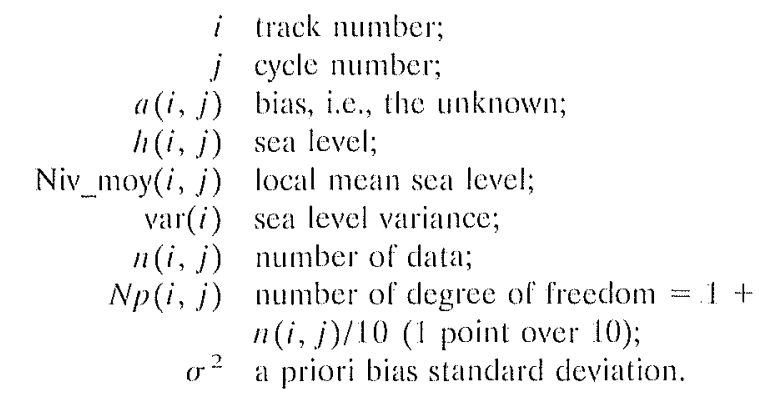

Overbar indicates an average over the track. The first term evaluates the distance to the local mean sea level defined as Niv moy $(i, j)$. The second term imposes a minimum-variance solution. Niv_moy $(i, j)$ is defined according to the unknown $a(i, j)$ by

$$
\begin{aligned}
& \operatorname{Niv}_{-} \operatorname{moy}(i, j)=\frac{1}{2} \frac{\sum_{i}[\overline{h(i t, j)}-a(i t, j)]^{2}[N(i t, j)]}{\sum_{i t} N(i t, j)} \\
& +\frac{1}{4} \frac{\sum_{i}[\overline{h(i t, j+1)}-a(i t, j+1)]^{2}[N(i t, j+1)]}{\sum_{i t} N(i t, j+1)} \\
& +\frac{1}{4} \frac{\sum_{i t}[\overline{h(i t, j-1)}-a(i t, j-1)]^{2}[N(i t, j-1)]}{\sum_{i t} N(i t, j-1)}
\end{aligned}
$$

It is the number of tracks used for the local mean level estimation. Neighboring tracks at less than $5^{\circ}$ of the track $i$ are used to estimate the local mean sea level, and data from cycles $j-1$ and $j+1$ are used to better constrain the local mean sea level.

The solution is found iteratively. Biases below $3 \mathrm{~cm}$ are not corrected for. The a priori bias standard deviation $\sigma$ is taken as $5 \mathrm{~cm}$. The a posteriori value is $3.52 \mathrm{~cm}$. The solution does not change the mean global level significantly.

Acknowledgments. This work was partially supported by the European Union under contract MAST2-CT93-0055. N. Ayoub benefited from a DRET fellowship.

\section{References}

Archiving, Validation, and Interpretation of Satellite Data in Oceanography, AVISO CD-ROM user manual for high level altimetric products, Publ. AVI-NT-02-400-CN, Ist ed., Cent. Natl. d'Etudes Spatiales, Toulouse, France, 1993.

Astraldi, M., G. P. Gasparini, and S. Sparnocehia, The seasonal and interannual variability in the Ligurian-Provencal Basin, in Seasonal and Interannal Variability of the Western Mediterranean Sea, Coastal Estuarine Stud., vol. 46, edited by P. E. La Violette, pp. 93-113, AGU, Washington, D. C., 1994.

Brasseur, P., J. M. Beckers, J. M. Brankart, and R. Schoenauen, Seasonal temperature and salinity fields in the Mediterranean Sca: Climatological analyses of an historical data set, Deep Sea Res., Pat $I /$, in press, 1995 .

Bryden, H. L., and T. H. Kinder, Recent progress in straits dynamics, Rev. Geoplys., 29, 617-631, 1991a.

Bryden, H. L., and T. H. Kinder, Steady two-layer exchange through the straits of Gibraltar, Deep Sea Res., Part A, 38, 445-463, 19916.

Bryden, H. L., and R. D. Pillsbury, Measurement of the flow through the straits of Gibraltar, Adv. Water Resour., 13, 64-69, 1990.
Bryden, H. L., and H. M. Stommel, Origin of the Mediterranean outllow, J. Mar: Res., 40, 55-71, 1982.

Candela, J., The Gibraltar Stants and its role in the dynamics of the Mediterranean Sea, Dyn. Amos, Oceans, 15, 267-300, 1991.

Candela, J., and C. L. Lozano, Barotropic response of the western Mediteranean to observed atmospheric pressure lorcing, in Seasonal and Incrammal Vaniability of the Westem Mediteranean Sea, Coastal Estharinc Stud., vol. 46, edited by P. E. La Violette, pp. 325-539, AGU, Washington, D. C., 1994.

Cartwright, D. E., and R. J. Tayler, New computations of the tidegenerating potential, Geoplys. J. R. Astron. Soc, 33, 253-264, 1971.

Crépon, M., lnluence de la pression atmosphérique sur le niveau moyen de la Méditeranée Occidentale et sur le flux a travers le détroit de Gibraltar, Cah. Oceanogr, 1, 15-32, 1965.

Fu, L., and G. Pihos, Determining the response of sea level to atmospheric pressure forcing using TOPEX/POSEIDON data, .t. Geopliys. Res., 99, 24,633-24,642, 1994.

Garrett, C., and F. Majaess, Noisostatic response of sea level to atmospheric pressure in the Eastern Mediterranean, I. P/ys. Oceanogr., $14,656-665,1984$.

Garrett, C., M. Bormans, and K. Thompson, Is the exchange through the straits of Gibraltar maximal or submaximal?, in The Physical Oceanograply of Sea Straits, edited by L. J. Pratt, pp. 271-294, Woods Hole Oceanogr. Inst., Woods Hole, Mass., 1990.

Gaspar, P., F. Ogor, P.-Y. Le Traon, and O. Z. Zanife, Estimating the sea state bias of the TOPEX and POSEIDON altimeters from crossover differences, J. Gcophys. Res., 99, 24,981-24,994, 1994.

Gill, A. E., and P. P. Niiler, The theory of the seasonal variability in the ocean, Deep Sea Res., 20, 141-177, 1973.

Harzallaly A., D. L. Cadet, and M. Crepon, Possible forcing effects of the net evaporation, atmospheric pressure, and transients on water transports in the Mediterranean sea, J. Geophys. Res., 98, 12,341$12,350,1993$.

Heburn, G., and P. E. La Voilette, Variations in the structure of the anticyclonic gyres found in the Alboran Sea, J. Geophys. Res., 95, $1599-1613,1990$.

Horton, C. J. Kerling, G. Athey, J. Schimtz, and M. Clifford, Airborne expendable bathythermograph surveys of the eastern Mediterranean, J. Geophys. Res., 99, 9891-9905, 1994.

Krisvoheva, V. G., and I. M. Ovchinikov, Pecularities in the geostrophic circulation of the waters of the Tyrmenian Sea, Oceanology, Engl. Transl., 13, 822-827, 1973.

Lacombe, H., Contribution à l'étude du détroit de Gibraltar, étude dynamique, Cah. Occanogr: XII, 73-107, 1961.

Lacombe, $\mathrm{H}$, and $\mathrm{P}$. Tchernia, Caractères hydrologiques et circulation des eaux en Méditerranée, in The Mediteranean Sea, edited by D. J. Stanley, pp. 25-36, Van Nostrand Reinhold, New York, 1972.

La Violette, P. E., Portion of the Western Mediterranean Circulation Experiment completed, Eos Trans. $A G U, 68(9), 123-124,1987$.

Le Traon, P. Y., and J. F. Minster, Sea level variability in the South Atlantic subtropical gyre: Semiannual Rossby waves and large-scale signal, J. Geoplys. Res., 98, 12,315-12,326, 1993.

Le Traon, P. Y., C. Boissier, and P. Gaspar, Analysis of errors due to polynomial adjustments of altimeter profiles, I. Almos. Oceanic Technol., $8,385-396,1991$

Le Traon, P. Y., J. Stum, J. Dorandeu, P. Gaspar, and P. Vincent, Global statistical analysis of TOPEX and POSEIDON data, I. Geophys. Res., 99, 24,619-24,631, 1994.

Malanotte-Rizzoli, P., and R. Robinson, POEM: Physical Oceanography of the Eastem Meditemanean, Eos Trans. $A G U, 69,4,1988$.

Millot, C., I. Taupier-Letage, and M. Benzohra, The Algerian eddies, Ean/h Sci. Rev., 27, 203-219, 1990

Millot, C., Mesoscale and seasonal variabilities of the circulation in the western Mediterranean, Dyn. Almos. Oceans, 15, 179-214, 1991

Ovchimikov, I. M., On the water balance of the Mediterranean sea, Oceanology, Engl. Transl., 14, 198-202, 1974.

Özsoy, E., A. Hetch, Ü. Ünlüata, S. Brenner, H. I. Sur, J. Bishop, M. A. Latif, Z. Roentratu, and T. Oguz, A synthesis of the Levanline Basin circulation and hydrography, 1985-1990, Deep Sea Res., Part II, 40, 1075-1119, 1993.

Pinardi, N., and A. Navarra, Baroclinic wind adjustment processes in the Mediterrancan Sea, Deep Sea Res., Pant I, 40, 1299-1326, 1993.

Ray, R. D., and B. V. Sanchez, Radial deformation of the Earth by oceanic tidal loading, NASA Tech. Memo., 100743, 1989.

Robinson, A. R., M. Golnaraghi, W. G. Leslie, A. Artegiani, A. Hecht, E. Lazzoni, A. Michelato, E. Sansone, A. Theocharis, and Ü. Ün- 
lüata, The eastern Mediterranean general circulation: Features, structure and variability, Dym. Atmos. Oceans, 15, 215-240, 1991.

Roussenov, V., E. Stanev, V. Artale, and N. Pinardi, A seasonal model of the Mediterranean Sea general circulation, J. Geophys. Res., 100, $13,515-13,538,1995$.

Speich, S., G. Madec, and M. Crepon, The circulation in the Alboran Sea: A sensitivity study, J. Phys. Oceanogr., in press, 1995.

Theocharis, A., D. Georgopoulos, A. Lascaratos, and K. Nittis, Water masses and circulation in the central region of the Eastern Mediterranean Ionian, South Aegean and Northwest Levantine, 19861987, Deep Sea Res., Part II, 40, 1121-1142, 1993.

Tintoré, J., P. E. La Voilette, I. Blade, and A. Cruzado, A study of an intense front in the Eastern Aloboran sea: The Almeria-oran Front, J. Phys. Oceanogr., 18, 1384-1397, 1988.
Tziperman, E., and P. Malanotte-Rizzoli, The climatological seasonal circulation of the Mediterranean sea, J. Mar. Res., 49, 411-434, 1991.

N. Ayoub and P. De Mey, Laboratoire d'Océanographie et de Géophysique, CNRS, 18 Avenue Edouard Belin, 31055 Toulouse, France. G. Larnicol and P.-Y. Le Traon, Collecte Localisation Satellites, Space Oceanography Groupe, 18 Avenue Edouard Belin, 31055 Toulousc, France. (e-mail: larnicol@metis.cnes.fir)

(Received February 22, 1995; revised June 27, 1995; accepted June 27, 1995.) 